\title{
Capacitance and Inductance based Rotor Ground Fault Location Method for Synchronous Machines
}

\author{
Ramanathan Palanisamy ${ }^{1}$
}

Received: 9 February 2014 / Accepted: 4 January 2016/Published online: 21 June 2016

(C) The Institution of Engineers (India) 2016

\begin{abstract}
This paper presents a capacitance and inductance based rotor ground fault location method for synchronous machines, which can detect and locate the ground fault in the rotor. The main contribution of this technique is to find the location of the ground fault in the rotor winding and reduce the repair time. This detection method is based on the measurement of inductance and capacitance of the rotor winding. It is suitable for salient pole synchronous machines. This method has been validated through experimental tests at the site.
\end{abstract}

Keywords Rotor Synchronous machine .

Fault location · Power system protection

\section{Introduction}

The use of protective devices in power systems is absolutely necessary in order to safeguard them against short circuits, overloads and in general, abnormal operations or faults. The protection system in generating units is especially important since it must reliably guarantee the power supply as per IEEE Standard C37.102 [1].

Some of the most common abnormalities such as vibrations and unbalanced stator voltages in synchronous generators are caused by ground faults in the rotor.

Generally, the first ground fault does not cause any damage to the machine, because the rotor winding circuit is ungrounded. However, the probability of a second fault

Ramanathan Palanisamy

ramanathaneb@gmail.com

1230 KV Sub-Station, Tamil Nadu Electricity Board, Kolappalur, Tamil Nadu, India increases after the first one since, it establishes a reference for voltages induced in the field by stator transients, thereby increasing the stress to ground at other points on the field winding. If this second fault occurs, the field winding will be partially short circuited, producing unbalanced fluxes in the machine, with the consequent vibrations and unbalance in the stator voltage. A double rotor ground fault could produce severe damage to the generator. Thus, the detection of a ground fault at the initial is more important.

Most rotor ground fault detection devices for synchronous generators are based on detecting abnormal values in certain electrical variables such as the stator no-load voltage [2] or the air gap flux [3] which can only detect double faults. However, a single ground fault cannot be detected with these techniques, because it does not produce any abnormality in the generator.

To achieve the early detection of the initial failure of the rotor to ground before severe damage occurs in the generator, a detection technique for synchronous generators with static excitation systems has been presented in [4]. In the event of higher excitation voltages, such as the ceiling voltage, the error in the rotor fault position estimate increases up to $13 \%$ [5]. A significant improvement over the detection technique with fuzzy rule based rotor ground fault location method has been presented in [6]. This paper aims to make a contribution to the field of fault location in synchronous machines, where there are already developments in ground fault location for the stator winding [7, 8], in fault location between the core laminations [9, 10] and even in insulation fault location using partial discharges $[11,12]$.

This paper presents a rotor ground fault location method that can be used in the salient pole synchronous machine without static excitation systems. This novel technique has two important advantages. 
(1) It could locate a ground fault on the dc side by capacitance based method of the rotor winding and the same could be ensured by inductance based method and vice versa.

(2) It is simple and does not need any additional injection source because it can measure the required physical parameters of the rotor winding by a single instrument.

As stated above, this paper presents a capacitance and inductance based rotor ground fault location method for salient pole synchronous machines. It is based on the variation of capacitance and inductance parameter of the rotor winding due to ground faults at different location of winding. This fact is of particular interest in the case of hydro generators because of the feasibility of removing one pole without requiring a complete rotor extraction. Moreover, the repair and maintenance operations of generators can be largely improved.

\section{State of the Art}

There are several methods for the detection of rotor field ground faults in synchronous generators [13, 14]. These detection methods generally require a ground connection and the use of an external ac or dc voltage source, or a lowfrequency signal-injector source. This section presents the most usual techniques [15].

\section{DC-Voltage Injection Ground-Fault Detection}

This technique consists of a dc voltage source in series with an overvoltage relay coil, both connected between an excitation brush (usually the negative side of the field winding) and ground. In the event of a ground fault, a current will flow through the relay causing it to actuate (Fig. 1).

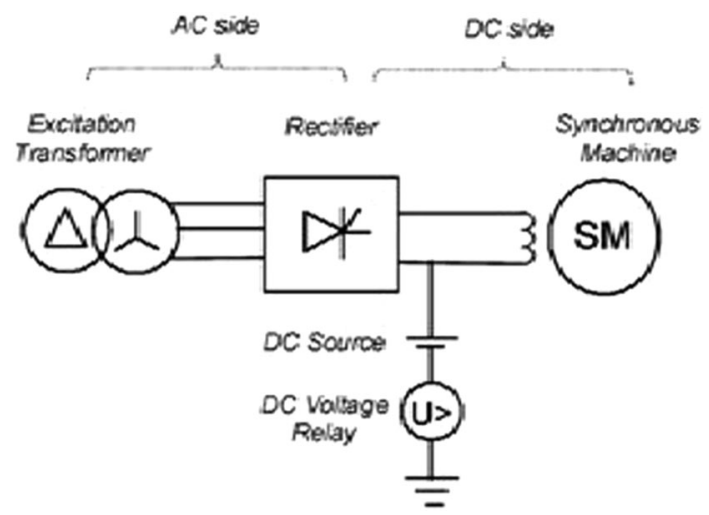

Fig. 1 DC-voltage injection ground-fault detection

\section{AC-Voltage Injection Ground-Fault Detection}

This detection system is based on a wheatstone bridge consisting of an ac voltage source ground connected in series with two capacitors (Fig. 2). Each capacitor is connected to the positive and negative terminals of the field winding. An over current relay measures the ac source current. During normal operation, a small current flows from the ac source (zero in theory). In the event of a ground fault, the current will increase and the relay will trip.

\section{Voltage Divider Ground-Fault Detection}

A voltage divider with a midpoint between the positive and negative terminals of the field winding and a sensitive overvoltage relay between the divider midpoint and ground should be installed. During normal operation, the voltage between the voltage divider midpoint and ground is zero, however, if a ground fault is present in the field winding, this voltage is not zero (Fig. 3).

If the fault is located at the end of the winding, the voltage measured by the relay will be at its maximum. However, in case of faults located at the midpoint of the field winding, the voltage across the relay would be zero. So, this scheme is not sensitive to faults closer to the midpoint of the field winding.

\section{Principles of the Rotor Ground Fault Location Method}

The procedure proposed in this paper utilizes both capacitance and inductance components to locate the rotor ground fault with $100 \%$ accuracy. A rotor winding circuit is the combination of all the three circuit parameters,

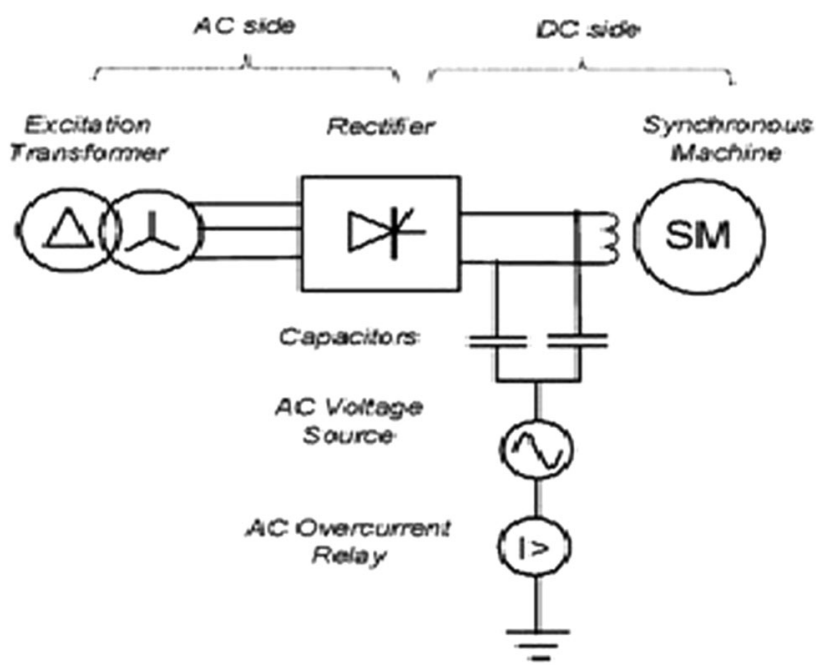

Fig. 2 AC-voltage injection ground-fault detection 


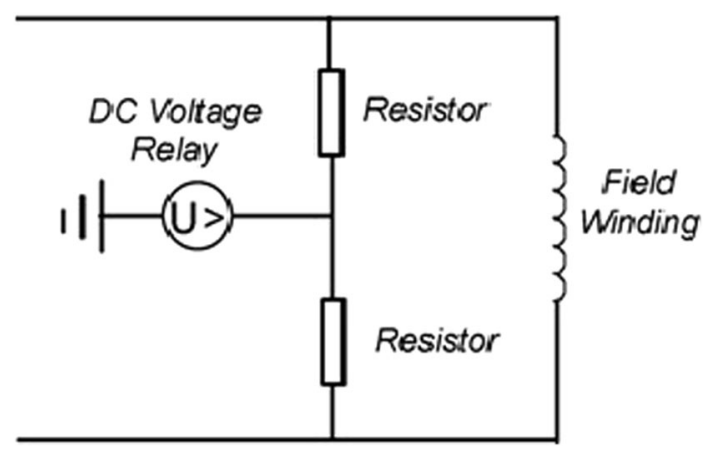

Fig. 3 Voltage divider ground-fault detection

namely, resistance, inductance and capacitance as shown in Fig. 4. Any abnormality in the geometry of the rotor winding will reflect on these parameters. In specific, it is observed that the salient pole rotor windings are very rich in inter-turn capacitance in the order of hundreds of microfarads which is quite useful in locating the faults with a higher degree of accuracy.

\section{Relationship Between Capacitance and Fault Location}

The principle behind this rotor ground fault location method is the relationship between the capacitive component in the salient pole rotor winding and the location of the fault along the winding.

The proposed ground fault detection method requires a simple meter for the measurement of capacitance of the rotor winding. The capacitance values between the rotor

Fig. 4 Synchronous machine rotor equivalent circuit

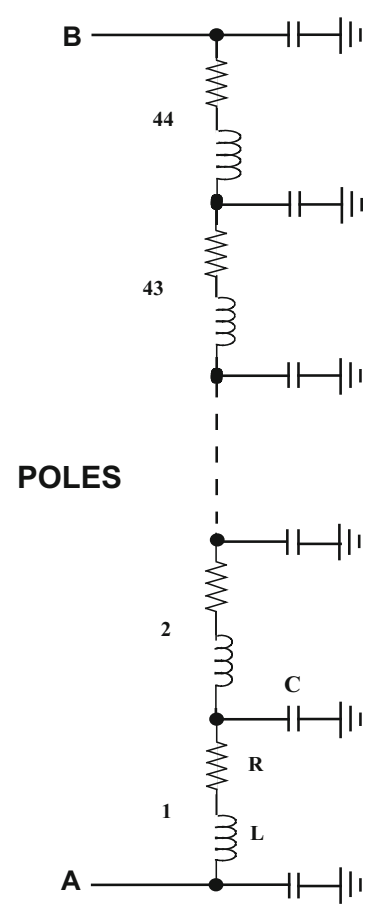

winding ends and the ground are measured. The location of ground fault could be easily detected from these values.

Figure 5 shows the rotor winding before ground fault. If the measurement value from $A$ to the ground is equal to the value from $B$ to the ground, then there is no evidence of ground fault, that is,

$\mathrm{C}_{\mathrm{A}-\mathrm{G}}=\mathrm{C}_{\mathrm{B}-\mathrm{G}}$

If solid ground fault occurs at any point between $\mathrm{A}$ and $\mathrm{B}$ as in Fig. 6, the measured capacitance values are not equal, that is, $\mathrm{C}_{\mathrm{A}-\mathrm{G}} \neq \mathrm{C}_{\mathrm{B}-\mathrm{G}}$. The difference in the capacitance value depends on the location of ground fault. Here, two sets of series pole capacitance circuits are formed due to the ground fault, from $A$ to $G$ and from $B$ to $G$.

Therefore, the fault location $\mathrm{F}_{\mathrm{L}}$ can be estimated according to the following expressions:

$F_{L}=\frac{C_{P}}{C_{A-G}}$

(OR) $\quad F_{L}=\left(N_{P}\right)-\left(\frac{C_{P}}{C_{B-G}}\right)$

where, $\mathrm{N}_{\mathrm{P}}$ represents the total no. of poles and $\mathrm{C}_{\mathrm{P}}$ represents the individual pole capacitance.

The fault location $F_{L}$ can be estimated using either Eqs. (2) or (3), both of which will yield the same result.

\section{Relationship Between Inductance and Fault Location}

The relationship between inductive component in the salient pole rotor winding and the fault location is similar to that of the relationship between the capacitive component and the fault location. The inductance values between the rotor winding ends and the ground are measured from A to ground and from B to the ground.

Before ground fault, the inductance between rotor winding to ground is nil, because there is no electric circuit in between them. After ground fault, two electrical circuits are formed in the rotor winding, from $A$ to $G$ and $B$ to $G$ (Fig. 6). The inductance values are now arrived between rotor winding and ground. The location of ground fault could be easily detected from these values.

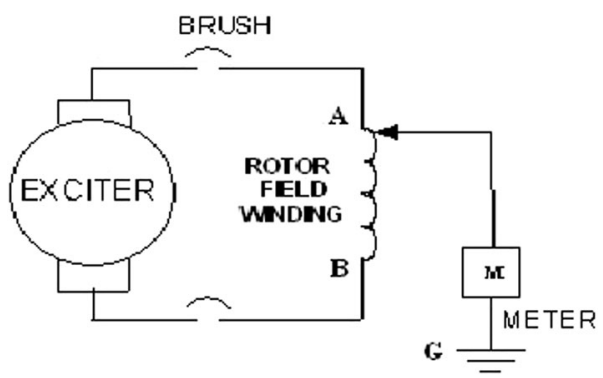

Fig. 5 Rotor field winding before ground fault 


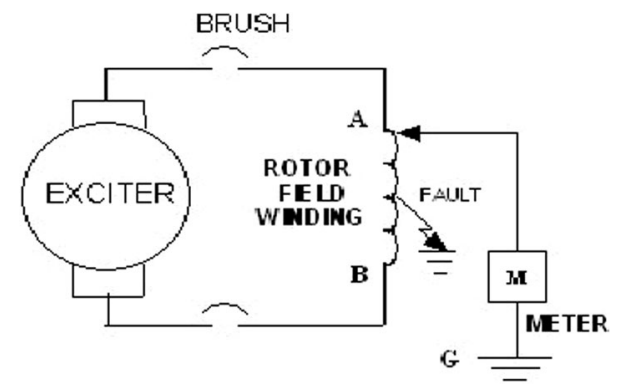

Fig. 6 Rotor field winding after ground fault

The difference in the inductance values depends on the location of the ground fault. Therefore, the fault location $\mathrm{F}_{\mathrm{L}}$ can be estimated according to the following expressions:

$F_{L}=\frac{L_{A-G}}{L_{P}}$

(OR) $\quad F_{L}=\left(N_{P}\right)-\left(\frac{L_{B-G}}{L_{P}}\right)$

where, $\mathrm{L}_{\mathrm{P}}$ represents the individual pole inductance.

All Eqs. (2), (3), (4) and (5) yield the same result to find the location of the rotor ground fault.

\section{Observations and Calculations}

The tests were conducted on rotor winding of a salient pole synchronous machine to test the validity of the proposed rotor ground fault location method. The test results are presented in Tables 1, 2, 3 and 4 .
Table 2 Capacitance values between rotor winding end and ground after fault

\begin{tabular}{llll}
\hline Test points & $\mathrm{C}, \mu \mathrm{f}$ & Test points & $\mathrm{C}, \mu \mathrm{f}$ \\
\hline A-G & 49.2 & B-G & 14.4 \\
\hline
\end{tabular}

Table 3 Inductance values between rotor winding end and ground after fault

\begin{tabular}{llll}
\hline Test points & $\mathrm{L}, \mathrm{mH}$ & Test points & $\mathrm{L}, \mathrm{mH}$ \\
\hline $\mathrm{A}-\mathrm{G}$ & 33.23 & $\mathrm{~B}-\mathrm{G}$ & 116.0 \\
\hline
\end{tabular}

The tests have been conducted on the rotor winding of a $50 \mathrm{MW}, 44$-pole synchronous machine (Table 5). In case, once the ground fault is detected, locating the fault can be a long and laborious process, especially with multi pole synchronous generators. In these cases, in order to determine the fault, the machine has to be removed from service. The connections between the rotor winding and the excitation system may have to be disconnected in order to locate the ground fault.

\section{Estimation of the Individual Pole Capacitance and Inductance}

The individual pole capacitance and the inductance values are estimated before commissioning of synchronous generator. These data are used to estimate the fault location after the ground fault. In order to estimate the individual pole capacitance $\left(\mathrm{C}_{\mathrm{P}}\right)$ and inductance $\left(\mathrm{L}_{\mathrm{P}}\right)$, the cumulative capacitance and inductance values from rotor winding end

Table 1 Capacitance and inductance measured on the rotor winding before ground fault

\begin{tabular}{|c|c|c|c|c|c|c|c|c|}
\hline Test points & $\mathrm{C}, \mu \mathrm{F}$ & $\mathrm{L}, \mathrm{mH}$ & Test points & $\mathrm{C}, \mu \mathrm{F}$ & $\mathrm{L}, \mathrm{mH}$ & Test points & $\mathrm{C}, \mu \mathrm{F}$ & $\mathrm{L}, \mathrm{mH}$ \\
\hline$A-1 \mathrm{a}$ & 688.2 & 2.442 & $A-16 a$ & 31.01 & 54.04 & $A-31 a$ & 16.07 & 104.3 \\
\hline$A-2 a$ & 274.7 & 6.112 & $A-17 a$ & 29.25 & 57.28 & $A-32 a$ & 15.49 & 108.2 \\
\hline$A-3 a$ & 177.9 & 9.435 & $A-18 a$ & 27.70 & 60.49 & $A-33 a$ & 14.95 & 112.1 \\
\hline$A-4 a$ & 130.1 & 12.89 & $A-19 a$ & 26.30 & 63.71 & $A-34 a$ & 14.47 & 115.8 \\
\hline$A-5 a$ & 102.8 & 16.29 & $A-20 a$ & 25.03 & 66.93 & $A-35 a$ & 14.03 & 119.5 \\
\hline$A-6 a$ & 85.24 & 19.68 & $A-21 a$ & 23.87 & 70.20 & $A-36 a$ & 13.60 & 123.3 \\
\hline$A-7 a$ & 72.53 & 23.09 & $A-22 a$ & 22.83 & 73.41 & $A-37 a$ & 13.20 & 127.0 \\
\hline$A-8 a$ & 63.29 & 26.48 & $A-23 a$ & 21.85 & 76.67 & $A-38 a$ & 12.82 & 130.8 \\
\hline$A-9 a$ & 55.95 & 29.96 & $A-24 a$ & 20.97 & 79.88 & $A-39 a$ & 12.47 & 134.4 \\
\hline A-10a & 50.15 & 33.41 & $A-25 a$ & 20.13 & 83.24 & A-40a & 12.15 & 138.0 \\
\hline A-11a & 45.47 & 36.84 & $A-26 a$ & 19.35 & 86.67 & $A-41 a$ & 11.85 & 141.5 \\
\hline$A-12 a$ & 41.49 & 40.39 & $A-27 a$ & 18.61 & 90.09 & $A-42 a$ & 11.56 & 144.9 \\
\hline$A-13 a$ & 38.13 & 43.94 & $A-28 a$ & 17.93 & 93.50 & $A-43 a$ & 11.32 & 148.2 \\
\hline$A-14 a$ & 35.37 & 47.38 & $A-29 a$ & 17.28 & 97.05 & $A-B$ & 11.20 & 151.6 \\
\hline$A-15 a$ & 33.00 & 50.76 & $A-30 a$ & 16.65 & 100.6 & & & \\
\hline
\end{tabular}


Table 4 Capacitance and inductance values between rotor poles and ground after fault

\begin{tabular}{lcccccccc}
\hline Test points & $\mathrm{C}, \mu \mathrm{f}$ & $\mathrm{L}, \mathrm{mH}$ & Test points & $\mathrm{C}, \mu \mathrm{f}$ & $\mathrm{L}, \mathrm{mH}$ & Test points & $\mathrm{C}, \mu \mathrm{f}$ & $\mathrm{L}, \mathrm{mH}$ \\
\hline $\mathrm{A}-\mathrm{G}$ & 49.20 & 33.23 & $15 \mathrm{a}-\mathrm{G}$ & 101.9 & 16.46 & $30 \mathrm{a}-\mathrm{G}$ & 25.17 & 65.17 \\
$1 \mathrm{a}-\mathrm{G}$ & 55.90 & 29.97 & $16 \mathrm{a}-\mathrm{G}$ & 84.76 & 19.80 & $31 \mathrm{a}-\mathrm{G}$ & 24.36 & 68.77 \\
$2 \mathrm{a}-\mathrm{G}$ & 63.05 & 26.58 & $17 \mathrm{a}-\mathrm{G}$ & 72.75 & 23.03 & $32 \mathrm{a}-\mathrm{G}$ & 23.14 & 72.41 \\
$3 \mathrm{a}-\mathrm{G}$ & 72.22 & 23.20 & $18 \mathrm{a}-\mathrm{G}$ & 63.91 & 26.22 & $33 \mathrm{a}-\mathrm{G}$ & 21.95 & 76.32 \\
$4 \mathrm{a}-\mathrm{G}$ & 85.00 & 19.74 & $19 \mathrm{a}-\mathrm{G}$ & 57.13 & 29.33 & $34 \mathrm{a}-\mathrm{G}$ & 20.89 \\
$5 \mathrm{a}-\mathrm{G}$ & 102.9 & 16.29 & $20 \mathrm{a}-\mathrm{G}$ & 51.60 & 32.47 & $35 \mathrm{a}-\mathrm{G}$ & 80.20 \\
$6 \mathrm{a}-\mathrm{G}$ & 130.2 & 12.88 & $21 \mathrm{a}-\mathrm{G}$ & 47.08 & 35.6 & $36 \mathrm{a}-\mathrm{G}$ & 19.97 \\
$7 \mathrm{a}-\mathrm{G}$ & 177.5 & 9.45 & $22 \mathrm{a}-\mathrm{G}$ & 43.21 & 38.78 & $37 \mathrm{a}-\mathrm{G}$ & 83.95 \\
$8 \mathrm{a}-\mathrm{G}$ & 274.5 & 6.11 & $23 \mathrm{a}-\mathrm{G}$ & 39.21 & 41.9 & $38 \mathrm{a}-\mathrm{G}$ & 18.12 \\
$9 \mathrm{a}-\mathrm{G}$ & 679.1 & 2.47 & $24 \mathrm{a}-\mathrm{G}$ & 37.16 & 45.07 & $39 \mathrm{a}-\mathrm{G}$ & 17.60 & 16.93 \\
$10 \mathrm{a}-\mathrm{G}$ & 0 & 0 & $25 \mathrm{a}-\mathrm{G}$ & 34.17 & 48.26 & $40 \mathrm{a}-\mathrm{G}$ & 91.49 \\
$11 \mathrm{a}-\mathrm{G}$ & 685.6 & 2.45 & $26 \mathrm{a}-\mathrm{G}$ & 32.50 & 51.55 & $41 \mathrm{a}-\mathrm{G}$ & 16.31 \\
$12 \mathrm{a}-\mathrm{G}$ & 274.3 & 6.11 & $27 \mathrm{a}-\mathrm{G}$ & 30.52 & 54.92 & $42 \mathrm{a}-\mathrm{G}$ & 102.8 \\
$13 \mathrm{a}-\mathrm{G}$ & 175.5 & 9.56 & $28 \mathrm{a}-\mathrm{G}$ & 28.76 & 58.27 & $43 \mathrm{a}-\mathrm{G}$ & 15.75 \\
$14 \mathrm{a}-\mathrm{G}$ & 128.3 & 13.07 & $29 \mathrm{a}-\mathrm{G}$ & 27.17 & 61.65 & $\mathrm{~B}-\mathrm{G}$ & 106.4 \\
\hline
\end{tabular}

Table 5 Name plate details of synchronous machine used in the experiment

\begin{tabular}{ll}
\hline "Electrosila" \\
\hline Named after S. M. Kiroy \\
\hline Three phase water wheel alternator \\
\hline Rated KVA & \\
Rated voltage & 56,000 \\
Frequency & $11,000 \mathrm{~V}$ \\
Stator current & 50 Cycles \\
Rotor current & $2940 \mathrm{~A}$ \\
Power factor & $1000 \mathrm{~A}$ \\
Connection & 0.9 \\
Rated speed & Star \\
Runway speed & 136.4 R.P.M \\
Type & 330 R.P.M \\
Sl No & CB $845 / 140-44-\mathrm{T}$ \\
Cooling air temperature & 361665 \\
\hline
\end{tabular}

State Standard 5616-50 Lenincrad 1963, Made in USSR

A to B (Fig. 7) are measured. In these cases, each pole capacitance and inductance values are added constantly to obtain the total rotor winding series capacitance $\left(\mathrm{C}_{\mathrm{T}}\right)$ and inductance $\left(\mathrm{L}_{\mathrm{T}}\right)$ value (Table 1$)$.

The individual pole capacitance and inductance values are calculated from Table 1 .

Total capacitance $\mathrm{C}_{\mathrm{T}}=11.2 \mu \mathrm{f}$

Total inductance $\mathrm{L}_{\mathrm{T}}=151.6 \mathrm{mH}$

Total number of poles $\mathrm{N}_{\mathrm{P}}=44$
Generally

$1 / \mathrm{C}_{\mathrm{T}}=\left(1 / \mathrm{C}_{1}\right)+\left(1 / \mathrm{C}_{2}\right)+\left(1 / \mathrm{C}_{3}\right)+\cdots+\left(1 / \mathrm{C}_{44}\right)$

$1 / \mathrm{C}_{\mathrm{T}}=\left(1 / \mathrm{C}_{\mathrm{P}}\right) \times \mathrm{N}_{\mathrm{P}}$

$1 / \mathrm{C}_{\mathrm{P}}=\left(1 / \mathrm{C}_{\mathrm{T}}\right) / \mathrm{N}_{\mathrm{P}}$

Individual pole capacitance $\mathrm{C}_{\mathrm{P}}=1 /\left\{\left(1 / \mathrm{C}_{\mathrm{T}}\right) / \mathrm{N}_{\mathrm{P}}\right\}$

Substitute the values in the above equation

$\mathrm{Cp}=1 / 0.002029=492.8 \mu \mathrm{f}$

The individual pole capacitance is $492 \mu \mathrm{f}$.

Individual pole inductance $\mathrm{L}_{\mathrm{P}}=\mathrm{L}_{\mathrm{T}} / \mathrm{N}_{\mathrm{P}}$

$\mathrm{L}_{\mathrm{P}}=151.6 / 44=3.44 \mathrm{mH}$

The individual pole inductance is $3.44 \mathrm{mH}$.

\section{Estimation of the Rotor Fault Location based on Capacitance}

In order to estimate the fault location, the capacitance values are measured between the end of the windings and ground. For example, a ground fault is created at a point 10a in-between pole 10 and 11 as shown in Fig. 8. The measured capacitance values between $A$ and $G$ and $B$ and $\mathrm{G}$ were not equal.

The values indicate the location of a ground fault, how far it is close or away from the end of winding (Table 2). However, the rotor winding end A to ground capacitance value is $49.2 \mu \mathrm{f}$ which is higher than $14.4 \mu \mathrm{f}(\mathrm{B}-\mathrm{G})$. The higher value of the capacitance indicates that the location of ground is closer to winding end A.

Simple calculation to estimate the fault location 
Fig. 7 Rotor winding total capacitance and inductance measurement layout

\section{ROTOR POLES}

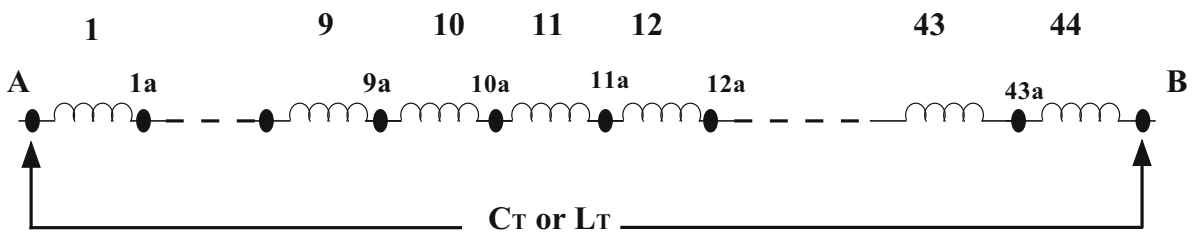

Fig. 8 Rotor fault location with capacitance measurement layout
ROTOR POLES

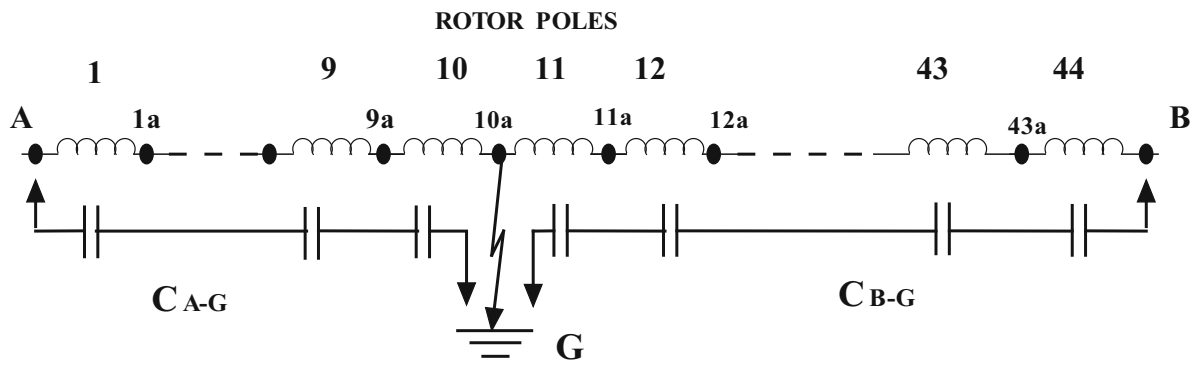

Substitute values in the Eq. (2)

$\mathrm{F}_{\mathrm{L}}=492 / 49.2=10$

(OR) Substitute values in the Eq. (3)

$\mathrm{F}_{\mathrm{L}}=44-(492 / 14.4) \approx 10$

Location of ground fault in the rotor winding is 10 th pole.

\section{Estimation of the Rotor Fault Location based on Inductance}

In order to estimate the fault location, the inductance values are measured between the end of the windings and ground. A ground fault is created at a point 10a in-between pole 10 and 11 as shown in Fig. 9. Here, two sets of electrical circuits are formed with respect to the ground. Now, the inductance values between $\mathrm{A}$ and $\mathrm{G}$ and $\mathrm{B}$ and $\mathrm{G}$ have been arrived.

The values also indicate the location of ground fault from the end of winding (Table 3). However, the rotor winding end A to ground inductance value is $33.23 \mathrm{mH}$ which is lower than $116.0 \mathrm{mH}(\mathrm{B}-\mathrm{G})$. The lower value of inductance indicates that the location of the ground fault is closer to winding end A.
Simple calculation to estimate the fault location Substitute values in the Eq. (4)

$\mathrm{F}_{\mathrm{L}}=33.23 / 3.44 \approx 10$

(OR) Substitute values in the Eq. (5)

$\mathrm{F}_{\mathrm{L}}=44-(116 / 3.44) \approx 10$

Location of ground fault in the rotor winding is 10th pole.

Normally, the individual pole capacitance and inductance values are measured and calculated before the ground fault and the data is held for future reference. If there is no previous data available in the faulted machine, the following method is used to detect the fault location easily. It is useful to detect the fault location without any calculated data.

To test the validity of the proposed rotor ground fault location method and to detect the fault location without any calculated data, measurement of capacitance and inductance values between each pole and ground is conducted. For example, the ground fault is created at a point 10a inbetween pole 10 and 11 and the values are measured and tabulated (Table 4).

The values plotted in the graph (Figs. 10,11) indicate the fault location by the fall at the 10th pole, since the test

Fig. 9 Rotor fault location with ROTOR POLES inductance measurement layout

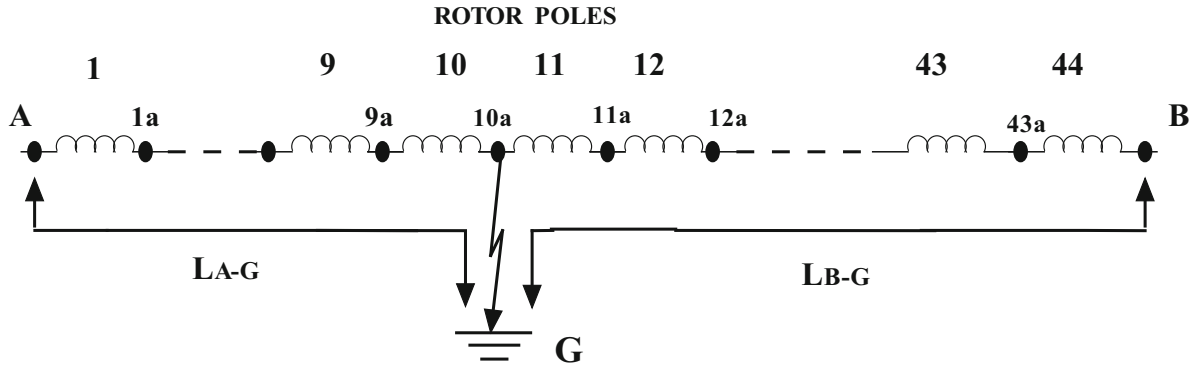




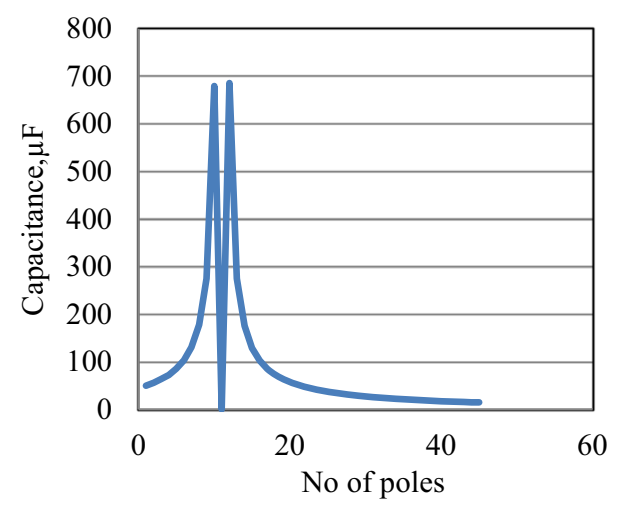

Fig. 10 Capacitance waveform for a fault at 10 th pole

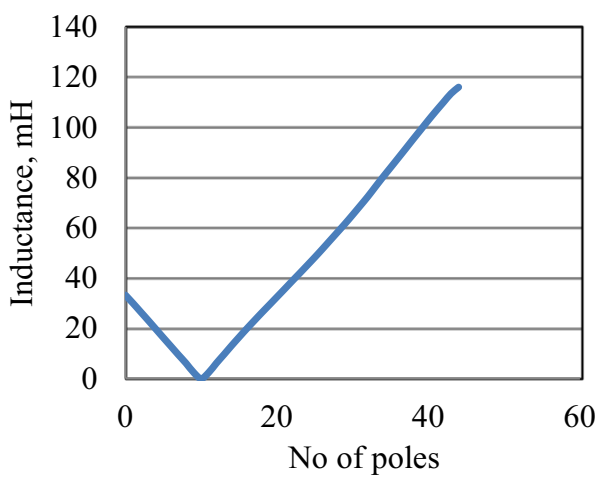

Fig. 11 Inductance waveform for a fault at 10th pole

point and reference point (ground) are the same. Before and after the fault location, the capacitance and inductance values changed constantly at each pole.

The waveforms confirm the results of fault location calculated from the Eqs. (2-5). The waveform does not require a expertise to identify the ground fault location. It is confirmed that the capacitance and inductance values between winding to ground are changed depending upon the fault location along the rotor winding. The salient pole rotor winding has higher side of capacitance and inductance value which is very useful to work out on steady results.

The accuracy of the estimate can be determined by knowing the fault position in advance and comparing the calculated position with the actual fault position. The location estimation errors were nil $(0 \%)$ in most cases. The location of ground fault can be easily found from the above methods if the ground fault is solid and permanent with negligible resistance.

\section{Conclusion}

A new capacitance and inductance based rotor ground fault location method has been presented in this paper. It is suitable for the salient pole synchronous machine. This method is accurate enough to detect and locate rotor ground faults. The applicability of the proposed method has also been verified by means of experimental tests with an actual synchronous machine.

This method is very simple, time saving and economical. This method requires a simple instrument and they need no electrical circuits. The main advantage of this method is that it contributes accurate information on the fault location after tripping the machine.

Having information on the location of a ground fault in the rotor winding saves time in the generator repair process. Moreover, in hydro generators, it might be feasible to remove one pole without resorting to a complete rotor extraction. This method can be used to design relay to detect the location of the rotor ground fault.

Acknowledgments The authors acknowledge the support and encouragement extended to Tamil Nadu Electricity Board, Kolappalur, Tamil Nadu, India.

\section{References}

1. IEEE Power Engineering Society, IEEE Guide for AC Generator Protection. IEEE Standard C37.102 (IEEE, New York, 2007)

2. M. Kiani, W-J. Lee, R. Kenarangui, B. Fahimi, Detection of rotor faults in synchronous generators. In: Proceedings of IEEE International Symposium Diagnosis Electric Machines, Power Electronics and Drives, pp. 266-271 (2007)

3. R.L. Stoll, A. Hennache, Method of detecting and modelling presence of shorted turns in DC field winding of cylindrical rotor synchronous machines using two air gap search coils. IEEE Proc. Electric Power Appl. 135(6), 281-294 (1988)

4. C.A.P. Gaona, F. Blázquez, P. Frías, M. Redondo, A novel rotor ground fault detection technique for synchronous machines with static excitation. IEEE Trans. Energy Convers. 18(4), 965-973 (2010)

5. C.A. Platero, F. Blazquez, P. Frias, M. Pardo, New on-line rotor ground fault location method for synchronous machines with static excitation. IEEE Trans. Energy Convers. 26(2), 572-580 (2011)

6. M. Mohanraj, R. Thttungal, M. Manobalan, Fuzzy based rotor ground fault location method for synchronous machines. IJAET 3(1), 247-254 (2012)

7. M. Zielichowski, M. Fulczyk, Analysis of operating conditions of ground-fault protection schemes for generator stator winding. IEEE Trans. Energy Convers. 18(1), 57-62 (2008)

8. M. Fulczyk, J. Bertsch, Ground-fault currents in unit-connected generators with different elements grounding neutral. IEEE Trans. Energy Convers. 17(1), 61-66 (2002)

9. S.B. Lee, G.B. Kliman, M.R. Shah, N.K. Nair, R.M. Lusted, An iron core probe based inter-laminar core fault detection technique for generator stator cores. IEEE Trans. Energy Convers. 20(2), 344-351 (2005)

10. G.B. Kliman, S.B. Lee, M.R. Shah, R.M. Lusted, N.K. Nair, A new method for synchronous generator core quality evaluation. IEEE Trans. Energy Convers. 19(3), 576-582 (2004)

11. A.J.M. Pemen, P.C.T. van der Laan, W. de Leeuw, Propagation of partial discharge signals in stator windings of turbine generators. IEEE Trans. Energy Convers. 21(1), 155-161 (2006)

12. J. Borghetto, A. Cavallini, A. Contin, G.C. Montanari, M. de Nigris, G. Pasini, R. Passaglia, Partialdischarge inference by an 
advanced system. Analysis of online measurements performed on hydrogenerator. IEEE Trans. Energy Convers. 19(2), 333-339 (2004)

13. R. H. Regan, K. Wakeley, Rotor monitoring and protection for large generators. In: Proceedings of IEEE Conference Publication no. 412 Electric Machines and Drivers, pp. 203-207 (1995)
14. P. Neti, A. B. Dehkordi, A. M. Gole, A new robust method to detect rotor faults in salient-pole synchronous machines using structural asymmetries. Presented at the IEEE Industry Applications Society Annual Meeting (IAS 2008), Edmonton, Alberta, Canada

15. Protective Relays Application Guide (GEC ALSTOM Protection \& Control Limited, Stafford, 1995), pp. 315-316 